\title{
HISTORIOGRAFIAS PERIFÉRICAS EM PERSPECTIVA GLOBAL OU TRANSNACIONAL: EUROCENTRISMO EM QUESTÃO
}

Peripheral historiographies in a global or transnational perspective: eurocentrism in question

Las historiografías periféricas en una perspectiva global o transnacional: el eurocentrismo en cuestión

\author{
PEDRO AFONSO CRISTOVÃO DOS SANTOS, \\ THIAGO LIMA NiCODEMO \\ e mateus Henrique de FARIa PEREIRA
}

http://dx.doi.org/10.1590/\$2178-14942017000100009

\footnotetext{
Pedro Afonso Cristovão dos Santos é doutor em História Social pela Universidade de São Paulo e professor da Universidade Federal da Integração Latino-Americana (pedro.cristovao@unila.edu.br).

Thiago Lima Nicodemo é doutor em História Social pela Universidade de São Paulo e professor adjunto da Universidade do Estado do Rio de Janeiro (tnicodemo@gmail.com).

Mateus Henrique de Faria Pereira é doutor em História pela Universidade Federal de Minas Gerais e professor da Universidade Federal de Ouro Preto (matteuspereira@gmail.com).

Os autores agradecem pela interlocução a André Lemos, Marcelo Abreu, Luisa Rauter, Carolina Figueira, Luiz Estevam Fernandes, Valdei Araújo, Guilherme Bianchi, Andre Voigt, Ana Lópes, Jefferson Queler, e a Elias Paltí e Ewa Domanska. Apoio: NEHM/UFOP, Laboratório Redes de Poder e Relações Culturais - UERJ, FAPEMIG, CAPES, CNPq, FAPERJ.

Artigo recebido em 15 de dezembro de 2016 e aprovado para publicação em 2 de fevereiro de 2017.
} 


\begin{abstract}
RESUMO
O presente artigo discute questões teóricas envolvidas na reflexão sobre a história da historiografia a partir das perspectivas global/transnacional. Examinando estudos de historiografia em contextos distintos, pensados em particular a partir dos estudos subalternos e dos estudos pós-coloniais, o artigo pondera o problema do uso de uma concepção de história e de historiografia gerada na Europa como base para uma reflexão global. Indagando as formas como essa prática historiográfica de matriz europeia viajou e foi apropriada em diferentes contextos, nossa pesquisa procura explorar as possibilidades de pensar a dinâmica centro-periferia para a produção do conhecimento histórico. Concomitantemente, o artigo estuda uma questão relevante colocada, em especial, pela história da historiografia preocupada com tradições periféricas: como pensar representações do passado não-ocidentais (como as de culturas indígenas) dentro da história da historiografia, ou em relação a esta, sem estabelecer uma hierarquia de saberes que atribua à concepção europeia de história um "privilégio epistêmico", nos termos do historiador indiano Sanjay Seth.
\end{abstract}

PalaVras-CHAVE: historiografia, estudos subalternos, estudos pós-coloniais, centro-periferia, eurocentrismo.

\title{
Abstract
}

The article discusses some theoretical issues involved in considering the history of historiography from a global or transnational perspective. By examining studies of historiography in different contexts, especially those elaborated on the basis of subaltern studies and postcolonial studies, it evaluates the problem of using an European conception of history and historiography as a basis for a global reflexion. By questioning the ways in which this historiographic practice of European matrix has travelled and has been appropriated in different contexts, we intend to explore the possibilities of using the center-periphery dynamic for the production of historical knowledge. The article also approaches a relevant question posited especially by the history of historiography that takes into account peripheral traditions: how to consider non-Western representations of the past (as those of indigenous cultures) in the light of a history of historiography, without establishing a hierarchy of knowledge that attributes to the European conception of history an "epistemic privilege", in the words of the Indian historian Sanjay Seth.

KEYWORDS: historiography; subaltern studies; center-periphery.

\section{RESUMEN}

En este artículo se describen problemas teóricos que intervienen en la reflexión sobre la historia de la historiografía de las perspectivas global y transnacional. Examinando los estudios de historiografia en diferentes contextos, pensados en particular a partir de los estudios subalternos y estudios postcoloniales, el artículo considera el problema de la utilización de una concepción de historia y de historiografía generada en Europa como base para una reflexión global. Indagando las formas como esta práctica historiográfica de origen europea viajó y fue apropriada en diferentes contextos, nuestra investigación busca explorar las posibilidades de pensar la dinamica núcleo-periferia para la producción de conocimiento histórico. Al mismo tiempo, abordamos una question relevante colocada en particular por la historia de la historiografía preocupada con tradiciones periféricas: cómo pensar las representaciones del pasado no occidentales (como las de las culturas indígenas) en la historia de la historiografía, o en relación con esta, sin establecer una jerarquía de conocimiento que atribui a la concepción europea de historia de un 'privilegio epistémico' conforme el historiador indiano Sanjay Seth.

Palabras clave: historiografía, estudios subalternos, estudios postcoloniales, centro-periferia, eurocentrismo. 
história da historiografia produzida no Brasil vive sob o signo de um paradoxo: a
maioria dos estudos tem como fonte e/ou objeto problemas, autores e/ou obras abordadas de uma perspectiva nacional/local, mas ao mesmo tempo essas fontes/objetos estão, do ponto de vista de sua historicidade, inseridas em "redes" transnacionais e/ou globais. Tendo em vista esse paradoxo, o presente artigo procura propor e apresentar reflexões teóricas sobre a possibilidade de pensar e produzir a história da historiografia em perspectiva transnacional, considerando em particular a história da historiografia latino-americana nessa perspectiva. Ao mesmo tempo, a fim de refletir sobre o referido paradoxo, fazemos considerações sobre algumas aporias que se colocam frente ao problema da inserção de distintas formas de representação do passado nessa história. Procuramos sintetizar algumas perspectivas a fim de problematizar, de um lado, uma história da historiografia fechada dentro das lógicas da nação e, de outro, uma "história intelectual global" pouco cuidadosa no que se refere às condições assimétricas de diversos tipos e eventualmente pouco atenta às ambiguidades encerradas no próprio conceito de modernidade e seus correlatos.

Este texto deve ser considerado como um primeiro esforço de síntese dessa questão, desenvolvendo um debate iniciado com a publicação do texto "Brazilian historical writing in global perspective" (History and Theory, 2015). Entendemos que os historiadores brasileiros podem dedicar mais atenção aos debates a respeito do eurocentrismo e da história global, e que as agendas de pesquisa podem efetivamente ganhar com o adensamento dessa reflexão. Em especial, em direção a uma ampliação da interlocução e da participação de historiadores brasileiros em debates internacionais, já que as tendências que trazem estes questionamentos, como os "estudos subalternos" e os "estudos pós-coloniais", vêm tendo forte ascendência no mundo nas últimas décadas. Mas também no sentido da ampliação de um repertório de temas de pesquisa, ferramentas conceituais e perguntas que se abrem quando refletimos acerca do enraizamento eurocêntrico e etnocêntrico das nossas representações históricas.

Assim, procuramos encarar com pragmatismo a noção de "eurocentrismo", entendida não só como as várias formas de influência política, econômica e social da Europa no globo, mas sobretudo como uma remissão ao enraizamento dos conceitos e valores que operam na ciência e em outras formas de enxergarmos o mundo. É curioso ressaltar um certo descompasso entre a pouca atenção a esse debate no plano acadêmico no Brasil, ao menos nos 
domínios da história da historiografia, história intelectual, teoria da história, entre outros, e a presença significativa que essa noção já ocupa, seja na demanda social pela inclusão social que impacta não só o ensino em geral como o perfil dos estudantes nas universidades, seja como conceito importante no ensino de história, que passa a influenciar a escrita e a difusão de livros didáticos, entre outros efeitos.

0 texto não "defende" ou advoga em prol da adesão às correntes dos "estudos pós-coloniais", "estudos subalternos", "história global" ou a qualquer outra. Entendemos ser necessário relativizar qualquer tipo de modismo e por isso procuramos dar um tratamento complexo e histórico aos conceitos, mas sem distorções em relação ao que pensam os autores cujas visões articulamos. Estas tendências têm a sua própria história e especificidade. Por exemplo, a noção de "história global" se adensou durante a década de 1990 em meio ao debate sobre a "globalização", mas conservou durante algum tempo uma visão positiva de base em relação ao fenômeno. Nesse contexto, o termo "global" ressaltava fenômenos de interdependência e processos de integração pelo planeta (Maurel, 2009; Mazlish, 1998).

Tendo em vista esses problemas, gostaríamos de pensar as possibilidades dos debates em torno do eurocentrismo, levando em consideração uma visão global que envolve a América Latina e outras nações consideradas periféricas como a Índia. Isso nos leva a uma reflexão sobre as possibilidades de uma história global autocrítica, que vá além da história da globalização como um dado positivo, universal ou inevitável (Davis, 2011; Vengoa, 2013). Para isso, dividiremos o texto em algumas partes que têm como eixo principal uma reflexão sobre as possibilidades de se pensar e fazer a história da historiografia em um viés crítico ao eurocentrismo. Nestas partes procuramos sublinhar o problema da representação do indígena na historiografia latino-americana, explorar o caso da disciplinarização da história na Índia, e refletir sobre as relações entre local e universal, centro e periferia, que levam finalmente à problematização da história enquanto um universal antropológico e a algumas sugestões de agenda de pesquisa a partir disso.

\section{AS HISTORIOGRAFIAS LATINO-AMERICANAS E OS PASSADOS INDÍGENAS: UMA HISTÓRIA DOS POVOS SEM HISTÓRIA?}

\footnotetext{
A problemática centro-periferia na história da historiografia assume preeminência se pensarmos nos momentos em que as narrativas de produção do conhecimento histórico, gestadas sob categorias geradas no "centro", devem lidar com representações do tempo, da memória e das tradições de culturas da "periferia" alheias àquelas categorias. No caso da América Latina, destacaremos a forma como as representações do passado das culturas
} 
indígenas foram incorporadas ou excluídas das histórias da historiografia no continente. Por uma questão de espaço não abordaremos outras tradições culturais, como, por exemplo, as derivadas da Diáspora Africana. Assim, dentro desse recorte, tal investigação pode ser feita, por exemplo, pelo exame da maneira como as crônicas e primeiras histórias desde a época da Conquista europeia foram sendo gradualmente transformadas em história da historiografia na América Latina, e de que forma essa história lidou com os registros das representações do passado indígenas.

Desde a década de 1830 sobretudo, coincidindo, pois, com as décadas pós-Independências na América Latina, em movimento que cresceu na segunda metade do século XIX e adentrou as primeiras décadas do século XX, foi preocupação dos autores de estudos históricos na América Latina a busca de documentos históricos em arquivos locais, nacionais (muitos deles organizados nesse período), europeus, além de coleções pessoais, para sua subsequente publicação em edições críticas singulares, periódicos ou coleções de documentos. Nomes considerados de grande importância na historiografia latino-americana entre os séculos XIX e XX, como Francisco Adolfo de Varnhagen e Capistrano de Abreu no Brasil, José Toribio Medina no Chile, Manuel Larrainzar e Edmundo O'Gorman no México, entre outros pelo continente, se destacaram nesse trabalho de edição de fontes históricas.

Sobressaía-se nessa prática a necessidade (política, patriótica, cívica) da escrita das histórias pátrias, as histórias nacionais, desde o pós-Independências. Para essa escrita, porém, era condição necessária a disponibilização das fontes, desde os primeiros registros escritos da chegada dos europeus até a documentação relativa à história contemporânea (cf., entre outros, Araujo, 2008) - documentos que fundamentaram processos de impactos e trocas globais de nacionalização, apresentação, representação e popularização de certos passados (Araujo, 2015; Lorenz, Berger e Melman, 2012).

Os historiadores desse período compreendiam sua tarefa como composta por vários saberes: história, etnografia, geografia, botânica, entre outros. Por isso, buscavam nos cronistas coloniais quase que seus "antecedentes" nesses campos do conhecimento. Vejamos, como exemplo, a maneira como Capistrano de Abreu se refere, em 1882, ao senhor de engenho do século XVI Gabriel Soares de Souza, autor de Tratado e Roteiro da década de 1580, editados por Varnhagen no século XIX: "A edição de Gabriel Soares é um trabalho de suma importância, pois Gabriel Soares é o geógrafo, o historiador, o etnologista, a enciclopédia viva do nosso século XVI". Recentemente, o mexicano Fermín del Pino-Díaz reeditou a Historia natural y moral de las Indias (1590), do padre Joseph de Acosta (anteriormente reeditada, em edição crítica, por Edmundo O'Gorman, em 1940). Em Joseph de Acosta, missionário jesuíta do século XVI, Pino-Díaz vê a possibilidade de pensar as origens da antropologia no México, pois o padre 
apresenta observações etnográficas que permitiriam ver ali, no primeiro século da Conquista, o início da etnografia na região (Sánchez Cuervo e Zermeño Padilla, 2014).

Independentemente de considerações que possamos fazer a respeito do anacronismo ou não dessas proposições (nos sentidos positivos e negativos da discussão sobre 0 anacronismo), interessa-nos aqui, pensando especificamente, o problema de uma história da historiografia de culturas não europeias por meio de registros produzidos justamente pelos cronistas europeus. Isto é, o próprio relato de eventos transcorridos era considerado histórico, ou historiográfico segundo os padrões da escrita da história ocidental de época (por isso Gabriel Soares de Souza fora bom "historiador", na observação de Capistrano de Abreu), mas como eram classificados os relatos que estes cronistas coletavam das versões dos povos não-europeus sobre seu próprio passado?

A principal edição crítica de Capistrano de Abreu foi a edição de 1918 da História do Brasil de Frei Vicente do Salvador, originalmente publicada em 1627. Sua apreciação do frei como historiador envolve critérios próprios da historiografia do início do século XX, mais do que dos preceitos pelos quais se guiaria o próprio Frei Vicente. A história que o religioso escreve do primeiro século da colonização portuguesa na América o qualifica como historiador, e a seu texto como historiográfico. Frei Vicente coletou também informações sobre os povos indígenas da região. Seu relato, porém, desconsidera qualquer versão para a origem ou migração dos indígenas para a América. Frei Vicente conta a versão recolhida por D. Diogo de Avalos, na Miscelânea Austral, sobre os Tupi e Guarani se originarem de dois irmãos com esses nomes, oriundos de tribos bárbaras da Espanha. Mas Frei Vicente descarta tal versão sobre o que chama de "origem do gentio do Brasil", bem como se recusa a registrar as demais versões que conhecera: "Esta opinião não é certa, e menos o são outras que não refiro, porque não têm fundamento: o certo é que esta gente veiu de outra parte, porem donde não se sabe, porque nem entre eles ha escrituras, nem houve algum autor antigo que delles escrevesse" (Salvador, 1918: 51). A "escritura", ou sua ausência, apresenta-se como o critério para apreciação de versões sobre "origens", o mais próximo que teríamos de uma "história" daqueles povos indígenas. Suas histórias, apenas orais, e registradas pelos europeus, não se qualificam como tal para figurar na História do Brasil de Frei Vicente, no início do século XVII. Seu editor, Capistrano de Abreu, no início do século XX, busca, nos comentários ao livro, apresentar a história dos deslocamentos e migrações indígenas através da relação entre suas línguas, remontando a um tipo de investigação já praticado em meados do século XIX no Brasil. Esse estudo não contava, porém, como história, mas, como demonstra Beatriz Christino, faz parte de uma rede transnacional de etnólogos interessados nas culturas latinas sul-americanas, entre as quais a rã-txa hu-ni-ku- i, em que circulava o próprio Capistrano (Christino, 2006: 39-45). 
Gabriel Soares de Souza, editado por Varnhagen em 1851, incluiu em seu relato sobre a Bahia a ocupação do território pelos povos indígenas, primeiramente os Tapuias, depois os Tupinaés e por fim os Tupinambás, segundo recolheu, atribuindo seu relato das guerras e migrações indígenas a "informações que se tem tomado dos índios muito antigos" (Souza, 1851: 305). Os portugueses por fim chegaram à Bahia, e a história indígena é conhecida, segundo Gabriel Soares, dos "Tupinambás e Tupinaés [dos quais] se tem tomado esta informação, em cuja memória andam estas historias de geração em geração" (Souza, 1851: 306). Segundo Varnhagen, Gabriel Soares "é singelo, quase primitivo no estylo, mas era grande observador, e, ao ler o seu livro, vos custa a descobrir se elle, com estudos regulares, seria melhor geographo que historiador, melhor botanico que corographo, meIhor ethnographo que zoologo" (Souza, 1851: X). As descrições dos primeiros cronistas em geral recaem sobre os mesmos costumes, com pouca atenção para a questão das origens dos povos indígenas. Por conseguinte, as representações do passado dos povos indígenas registradas pelos cronistas europeus foram subsumidas sob a própria escrita da História como a entendiam os cronistas europeus (e posteriormente seus editores e comentadores latino-americanos), excludente das versões de representar e se relacionar com o passado presentes nos povos indígenas.

No século XIX, na base de tal exclusão estava uma distinção que, ao mesmo tempo em que impulsionou os estudos sobre os indígenas, os "excluiu" da História. Essa distinção pode ser resumida pelo pensamento de Francisco Adolfo de Varnhagen: um dos artífices da criação da seção de Etnografia do Instituto Histórico e Geográfico Brasileiro, e defensor do estudo das línguas indígenas, Varnhagen argumentava que a etnografia era o espaço para o conhecimento sobre os indígenas, e não a história; pois esses povos seriam, segundo ele, "povos sem história", isto é, povos sem transformações significativas em seu modo de vida ao longo do tempo (os povos sem história no pensamento europeu oitocentista.) Os indígenas não teriam, pois, nem história, nem historiografia. Suas próprias concepções de tempo e relatos de origem eram descartados enquanto história, e restavam como testemunhos de sua mentalidade. Ou seja, uma manifestação do "privilégio epistêmico" da forma europeia de representar o passado sobre outras tradições (Seth, 2013). Nas palavras de Rodrigo Turin (2012: 783), tendo em vista o caso brasileiro, "o discurso etnográfico oitocentista era concebido, pelos próprios sócios do IHGB, como um modo específico de escrita da história. À etnografia caberia trazer à visibilidade novamente aquilo que os indígenas, por si sós, não poderiam resgatar através de uma memória: seu passado". 


\section{O CASO INDIANO: INSTITUCIONALIZAÇÃO E ENCLAUSURAMENTO DA HISTÓRIA E DO HISTORIADOR?}

C hakrabarty (2015) assinala que a história afirma-se como disciplina na prática dos historiadores indianos antes de sua verdadeira institucionalização nas universidades, processo semelhante ao que ocorre na América Latina (em especial no Brasil). Evidentemente, as diferenças também são significativas, embora não de todo excludentes. A relação entre historiografia e nacionalismo, por exemplo: na Índia, tal associação se dá antes da independência do país (1947), enquanto na América Latina, em linhas gerais, a imbricação entre nacionalismo e historiografia se dá após as Independências, como parte dos discursos de legitimação e autoafirmação das novas nações.

0 autor pontua, ao longo de seu estudo, possibilidades de pensar a historiografia em perspectiva transnacional. Para ele, a formação da história como disciplina na Índia teve muito a ver com a interação entre dois lados da historiografia: o que chama de "cloistered life of history" (a vida enclausurada da história/historiador), isto é, a prática dos historiadores nos arquivos e gabinetes, e os diálogos internos à comunidade dos mesmos; e a vida pública ("public life") da história (Chakrabarty, 2015: 7-8), isto é, debates que mobilizavam a história, como aqueles referentes a identidades nacionais, regionais, étnicas e religiosas. A resposta dos historiadores a essas pressões públicas moldou, segundo Chakrabarty, o que veio a ser a historiografia acadêmica indiana (entre o final do século XIX e início do século XX, período aproximado ao do mesmo fenômeno na América Latina). Por isso o autor chama sua pesquisa de "the popular origins of academic history in India" (Chakrabarty, 2015: 12), em razão dessa interação entre a historiografia acadêmica e concepções populares de história.

Chakrabarty considera que a "vida enclausurada" da história "may look the same everywhere, with minor variations. We may even be able to provide this cloistered life of the discipline with more-or-less global histories, such as in books on the general history of historiography" (Chakrabarty, 2015: 8). Ou seja, seria possível, e até aqui foram feitas, histórias gerais da historiografia baseadas exclusivamente na vida dos arquivos, dos gabinetes, e dos debates entre historiadores. Embora Chakrabarty reconheça essas histórias da historiografia como histórias de "different traditions of historical writing", seu argumento principal é que o que dá especificidade a uma tradição historiográfica é estar "embedded in different public contexts in very different ways". Segundo Chakrabarty (2015: 8), "not only the 'nature of historical writing' that is influenced by the places in which such writings are produced; the valence of even the basic categories of the discipline - such as 'research', 'facts', 'truth', 'evidence', 'archives' - can be molded by the interaction between history's cloistered and public lives". Seu estudo 
procura mostrar, de fato, como esses termos básicos, como pesquisa ("research") e verdade (" truth") são marcados pelo contexto e tradição local da historiografia indiana.

Através de Jadunath Sarkar, seu objeto de estudo, Chakrabarty mostra a transição para uma ideia de pesquisa baseada na noção de verificação das fontes. De fundo, estava também a ideia de verdade, que Chakrabarty compara à sua presença (e uso) em Leopold von Ranke. Porém, o contexto indiano cobra sua especificidade: como aponta Chakrabarty, se a devoção à verdade em Ranke seria uma versão secular da ideia protestante de vocação para o serviço religioso, em Jadunath Sarkar o lugar de Deus fora ocupado pela ideia de nação. Sua visão de nação inspiraria sua visão do trabalho do historiador como "vocação", "vocação à verdade" (a call to truth). Aqui, todavia, vemos uma interessante abordagem do que poderia ser uma dinâmica centro (Europa) - periferia (Índia) aparecer no estudo de Chakrabarty:

Sarkar's sense that there was something spiritually lofty about this commitment to historical truth was, however, no mere copy of Ranke's Protestantism or some other European creed. He had translated the Rankean urge into Hindu-mystic categories and drew on traditions that belonged to the metaphysics of a certain variety of Hindu nationalism that, by his time, had both politicized and spiritualized the word truth itself - witness Gandhi's use of the word satya (truth) in satyagraha (...). This translational turn was once again clear in Sarkar's use of the Sanskrit word chittashuddhi - the act of cleansing (shuddhi) one's mind or consciousness (chit) - while responding to an occasion in the early 1950s when his admirers organized a formal celebration of his achievements (Chakrabarty, 2015: 76).

Uma mesma necessidade, ou anseio, por verdade, e uma semelhante noção de ascese ou vocação para a erudição histórica podem ser comparadas em Ranke e Sarkar. Porém, apenas uma imersão na tradição cultural e no contexto histórico específico indiano permitiria a compreensão dos valores daquela historiografia, e assim sua inserção em uma perspectiva global da história da historiografia.

Chakrabarty contempla, mas rejeita, a ideia de uma perspectiva comparativa para seu estudo de Jadunath Sarkar (Chakrabarty, 2015: 34). Poderíamos estudar uma historiografia particular em perspectiva comparada, segundo ele, por meio da comparação de diferentes atitudes (em relação a fontes e arquivos, por exemplo); pensando a conexão entre historiografia moderna e nacionalismo em regiões colonizadas ou dominadas pelos europeus; ou refletindo sobre historiadores e eruditos como praticantes de "formas de vida" específicas, estudando as ideias de ascetismo presentes nessas formas. Chakrabarty vai, por seu lado, na direção de pensar o surgimento da historiografia disciplinar na Índia por meio do estudo de ideias, instituiç̧ões e práticas centrais a esse processo de disciplinarização, como as ideias de fato e verdade e as práticas de pesquisa documental. 


\section{AS HISTORIOGRAFIAS LATINO-AMERICANAS: ENTRE O "CENTRO” E A "PERIFERIA"?}

A ideia de uma historiografia composta de sua vida no "claustro" e sua vida no espaço público, onde o "claustro" possui padrões e noções semelhantes em diferentes contextos, tem em seu cerne a questão da interação entre as duas vidas. Como a prática do "claustro" viaja de contexto a contexto? Como se dá a recepção dessas práticas e noções em diferentes espaços? Chakrabarty assinala que, em linhas gerais, o que dá o caráter específico a uma historiografia local é a vida pública da história. Porém, pode a recepção às práticas do ofício do historiador se dar de tal maneira que os debates públicos, antes de moldar a historiografia, são eles mesmos moldados por ela? É aqui que o debate centro-periferia se mostra ainda pertinente, em nossa visão. No caso latino-americano, o problema da recepção e apropriação das ideias e práticas historiográficas europeias, sobrepondo-se à cultura local (e estabelecendo uma relação específica com a "vida pública" da história) no continente gerou a interpretação de que a historiografia latino-americana pode ter se estabelecido, no século XIX, em contraposição à cultura local - isto é, como a transposição de "ideias fora do lugar".

O historiador colombiano German Colmenares trabalhou essas questões no livro Convenciones contra la cultura (1986). Em sua visão, os historiadores hispano-americanos (Colmenares excluiu a historiografia brasileira e, grosso modo, ateve-se apenas aos historiadores da América do Sul de língua espanhola) do século XIX escreveram as primeiras histórias nacionais pós-Independências, as historias pátrias, valendo-se de "convenções" de escrita da história europeias, criando assim narrativas que iriam contra as culturas nacionais latino-americanas daí o título de seu livro. Por exemplo, buscaram na história de seus países "Grandes Homens", heróis à moda de Thomas Carlyle. Interessante que Colmenares excluiu a historiografia brasileira e, grosso modo, ateve-se apenas aos historiadores da América do Sul, o que remonta a uma polêmica sobre o lugar do Brasil em uma "história universal da América", como havia sugerido Joaquim Nabuco (Marquese e Pimenta, 2015: 33).

Por "convenções" Colmenares queria dizer, basicamente, a estrutura das narrativas, os temas e esquemas de representação (ou figuração) da história; algo semelhante a modos e tropos literários. Em suas palavras,

Los historiadores hispanoamericanos del siglo XIX emplearon las convenciones que dominaban entonces en la historiografía europea. Dichas convenciones se originaban en una renovación de las formas de representación frente a la llustración y al neoclasicismo, y traducían, como retórica, un contexto ideológico y cultural europeo. Por esto la recepción de tales convenciones propone dos problemas. Uno, su análisis como formas particulares de figuración de la realidad. 
Otro, el de un posible conflicto entre convenciones destinadas a representar una realidad cultural extraña, de la cual hacian parte, y la realidad cultural especifica de Hispanoamérica. El riesgo de emplearlas consistía en que las convenciones se revelaran más fuertes que la realidad que debian transmitir, que los esquemas figurativos o los patrones de una narrativa distorsionaran realidades sociales y culturales que requerian un desplazamiento de esas convenciones para su comprensión (Colmenares, 1986: XXI).

Por conseguinte, essa particular interação centro-periferia na produção do conhecimento histórico na América Latina do século XIX deixa como problemas: em primeiro lugar, pensar as convenções utilizadas pelos historiadores como " formas particulares de figuración de la realidade". Enquanto na Europa houve um "paralelismo" entre o desenvolvimento narrativo do romance e da historiografia, dentro do qual a historiografia se enriqueceu e ampliou suas possibilidades de explorar emoções, ações e reações, bem como deslocamentos temporais, no caso latino-americano do Oitocentos, argumenta Colmenares, "las formas de representación fictiva se limitaron al costumbrismo. La observación costumbrista buscaba amoldarse a un mundo tradicional, casi inmóvil, en el que la novedad que podia introducir el libre juego de las emociones era prácticamente inexistente" (Colmenares, 1986: XXII). ${ }^{1}$

0 segundo problema nos faz pensar no debate sobre as "ideias fora do lugar". ${ }^{2}$ Diz respeito à operação de distorção e deslocamento da realidade local visando seu encaixe no molde, na convenção historiográfica (alienígena) utilizada. Ambos os problemas, porém, não apenas não impedem, como antes convidam ao estudo de uma história cultural unificada da Hispanoamérica, ou, em termos alheios a Colmenares, a uma história cultural transnacional, que visualize uma unidade histórica que exceda os limites dos Estados nacionais. "Hoy es concebible - algunos dirían que deseable y hasta necesaria - una historia temáticamente unificada de Hispanoamérica" (Colmenares, 1986: XXVII). Essa perspectiva seria impossível de ser vista no século XIX, segundo Colmenares, quando as partes do antigo Império espanhol se viram presas em suas próprias lutas intestinas e dramas particulares. "Pero si se prescinde de las complejidades dramáticas de la trama, no son en el fondo estas historias una experiencia común hispano-americana? En otras palabras, no hablan un mismo lenguaje?"

Si el análisis de las historias nacionales se desplaza desde su encadenamiento factual hacia los medios de su representación narrativa, si la diversidad de "historias" se toma como un texto único para mostrar las convenciones con las cuales se construyen, muy pronto se revela que este procedimiento no constituye un artificio de tipo estructuralista, sino una posibilidad de reflexionar teóricamente sobre el fenómeno de las "historias patrias" (Colmenares, 1986: $X X V I I I)$. 
Isto é, estudamos a história da historiografia hispano-americana em conjunto se deixamos de pensar nos fatos particulares concatenados pelas diferentes narrativas nacionais, e atentamos para as convenções que estruturam essas narrativas, sua estrutura. 0 que leva à necessidade de uma postura teórica por parte do historiador que lhe permita analisar essas estruturas narrativas.

A possibilidade de estudar em conjunto a historiografia latino-americana foi expandida pelo também colombiano Sergio Mejía, em "La noción de historicismo americano y el estudio de las culturas escritas americanas" (2009). Mejía propõe incluir todo o continente americano, as historiografias em língua espanhola, portuguesa, inglesa e francesa, por meio do conceito de historicismo americano: "con la noción de historicismo americano me refiero, pues, a una biblioteca de historias republicanas que comandan autoridade en su pais" (Mejía, 2009: 252). Mejía baseia seu conceito na percepção de uma necessidade compartilhada em todo o continente de narrar, descrever, comentar e legitimar as novas repúblicas americanas. Desde 1776, desde a independência dos EUA, tal fenômeno ocorreria. Esse conceito valeria para o estudo da cultura escrita americana, do sul da América do Sul ao Canadá. Os anos pós-Independência produziram narrativas que acabariam assumindo estatuto de cânones na representação do passado e na legitimação das repúblicas no continente. 0 historicismo americano, enquanto "biblioteca", coleção de escritos históricos, se organiza em especial a partir do que Mejía chama de "histórias monumentais", obras de história nacional in cuarto ou octavo, em geral em mais de um volume, das quais as centradas nas revoluções de independência seriam particularmente importantes. Também compõem o corpus do historicismo americano o que Mejía chama de histórias gerais (as que incorporavam o período colonial e, em alguns casos, pré-hispânico), obras menores (como coleções de documentos e compêndios) e obras temáticas (como histórias da literatura, das artes, da Igreja). Desse modo, é uma operação conceitual que baseia a análise historiográfica transnacional. A ideia de que todas as culturas escritas americanas, desde o fim do século XVIII, em tempos e percursos diferentes, tiveram a necessidade de produzir histórias republicanas, permite a articulação de toda essa produção historiográfica em um escopo temporal e conceitual únicos. Um particular anseio, uma necessidade por história, permite relacionar as diferentes tradições nacionais. Não custa perguntar aqui em que medida 0 caso brasileiro se configura, de fato, como uma exceção.

Como afirmam Iggers, Wang e Mukherjee (2008: 5-7), de fato a missão de uma história global será verificar as interações produzidas das matrizes disciplinares da história tal como foram estabelecidas entre os séculos XVIII e XIX a partir do caso alemão. No entanto, é necessário relativizar a ideia de relações rígidas de "influência" entre centro e periferia na 
modernidade, aprofundando o conhecimento de experiências periféricas. Não se trata apenas da "adaptação criativa" dos padrões ocidentais de história, mas de como os próprios modos de se fazer e pensar a história sofrem modificações significativas. ${ }^{3}$ Não custa lembrar que a experiência moderna de história foi modelada no contato com o "outro", seja "ocidental" el ou "oriental".

A partir desses desenvolvimentos das formas disciplinares da história no Ocidente, poderíamos ser levados a pensar que a América Latina está numa posição periférica, ou mesmo secundária, tendo se desenvolvido apenas tardiamente. Mas, ao contrário, de acordo com Guillermo Zermeño Padilla (2008), João Paulo Garrido Pimenta e Valdei Lopes de Araujo (2009), no que se refere à "experiência do tempo", podemos dizer que a afirmação do conceito moderno de história (como Geschichte) na América Latina e das formas disciplinares correlatas não é muito posterior ao caso da Alemanha, ocorrendo na primeira metade do século XIX a partir da experiência política das independências no continente, que abrem caminho para o novo espaço de experiência da modernidade.

A apropriação das categorias de Koselleck pela historiografia latino-americana compõe apenas um fragmento de um debate mais amplo a respeito da natureza da experiência periférica de modernidade. Em outras palavras, sobre como valores burgueses e liberais circulam pelo Novo Mundo, respondendo a uma oscilação complexa entre experiência, conceitos e linguagens (cf., por exemplo, Araujo, 2015b). Falando de forma muito geral, o passado colonial representou para muitos historiadores do século XIX, entre os quais o próprio Varnhagen, um elemento chave na formação da nação no presente.

Com o passar das décadas e indo em direção ao século XX, a história se transformou no meio mais importante para o debate sobre modernização, já que a principal condição para a modernidade era lidar com o passado colonial. Nesse ponto, o conceito moderno de história atinge sua forma sistemática e madura, ancorado na dinamização da opinião pública. Em uma tendência interpretativa que vai se solidificando com as primeiras décadas do século XX e que identificamos como "ensaísmo social", representada no Brasil por Manoel Bomfim, Paulo Prado, Sérgio Buarque de Holanda, entre outros, a herança do passado colonial tinha de ser identificada, estudada e superada de modo a abrir espaço para uma nova era. É, pois, possível falar de nacionalização do passado, de um uso programático do passado, de um certo espaço de experiências, todavia marcado por um horizonte de expectativas altamente projetável no Brasil. Além do caloroso debate na imprensa no qual essas discussões eram moldadas e se tornavam tangíveis, emerge um tipo de ensaio, uma forma híbrida que mescla política, estética e ciências sociais que não é típica apenas do Brasil, mas está em claro diálogo com o pensamento latino-americano da mesma época. 
Como, pois, repensar a história da historiografia de um modo que busque essas outras representações do passado, pois, como afirma Dipesh Chakrabarty, a vida "enclausurada" da história disciplinar (isto é, a vida dos arquivos, da escrita acadêmica) varia pouco entre contextos culturais distintos? A análise e cruzamento de diversos regimes de relativa autonomia intelectual (Araujo, 2015a) em perspectiva transnacional pode indicar algumas soluções para o problema apontado. Igualmente interessante seria mostrar as relações complexas entre as pressões públicas e as configurações da incipiente disciplina.

Como vimos, os estudos de história da historiografia têm se orientado a partir de referenciais teóricos que têm permitido aos pesquisadores uma linguagem comum no intercâmbio de suas ideias. Um desses referenciais tem sido, certamente, a obra de Reinhardt Koselleck, em particular sua investigação sobre a mudança do conceito de História entre o século XVIII e - XIX (grosso modo, de 1750 a 1850). Isto é, a passagem de uma "história mestra da vida", legitimada pelo fornecimento de lições morais extraídas de exemplos do passado, para uma história progressiva e voltada para o futuro, que se vê fundamentalmente diferente do passado. Uma nova experiência de tempo surge, orientada para os projetos de porvir. Essa nova experiência de tempo caracterizaria, na visão de Koselleck, a modernidade.

Seu argumento teve, e tem, forte impacto na história da historiografia latino-americana (Guillermo Zermeño Padilla, Valdei Lopes de Araujo e todos os outros pesquisadores ligados de algum forma ao Projeto Iberoamericano de História Conceitual, por exemplo). Deixa, porém, a dúvida a respeito das possibilidades de falarmos em modernidade e mesmo em história fora da tradição europeia inaugurada neste período de 1750 a 1850. Como pensar outras concepções do que poderíamos também chamar de história? Ou, ao menos, pensar se a história da historiografia não se apoia sobre uma aporia: sendo a história um produto da modernidade europeia, do período 1750-1850, é possível falar de fato em outras tradições historiográficas, não-ocidentais? É possível uma história da historiografia "global", que incorpore tradições que estariam fora do que poderia ser considerado história?

Como veremos mais à frente, procuramos sublinhar a importância do estudo das trocas e interações que enfatizem a natureza não isonômica das realidades imbricadas no sistema capitalista. Ao mesmo tempo, sugerimos cautela na mobilização de conceitos tão genéricos como "centro", "periferia" e "modernidade". A condição periférica que pauta as trocas intelectuais desiguais deve ser avaliada na sua historicidade, por meio de uma investigação cuidadosa a respeito dos significados que cada indivíduo atribuía ao pensamento e à experiência histórica. 


\section{O NACIONAL VERSUS O LOCAL E A ESCRITA DE UMA HISTÓRIA "GLOBAL"}

S s abordagens transnacionais, ou globais, bem como as chamadas "histórias conectaestritamente comparativo, que considera os Estados nacionais como polos de comparação. 0 historiador indiano Sanjay Subrahmanyam, por exemplo, afirma que, ao pensar a ideia de história conectada, buscava em primeiro lugar se contrapor à história nacional, definida por ele como "a ideia de um comparatismo em que os objetos comparados seriam os Estados-nação" (Boucheron, Delalande, 2015: 50). A respeito de sua pesquisa, em particular, Subrahmanyam afirma que ficou interessado no que chama de "ideia do mundo eurasiático, de modo que me debrucei sobre a conexão entre o mundo do Mediterrâneo, os otomanos, o Irã, a Índia e mesmo a Ásia do Sudeste" (Boucheron, Delalande, 2015: 52).

A crítica de Subrahmanyam integra uma perspectiva revisionista do pós-colonialismo e estudos culturais em relação à história comparada. Historicamente constitutiva sobre as bases disciplinares da história no século XX (Detienne, 2004), a história comparada não teria abandonado o Estado-nação como parâmetro, o que acaba por obliterar as possibilidades de leituras interconectadas (Purdy, 2011: 65). Assim como Michael Werner e Bénédicte Zimmermann, caberia então não pensar o comparativismo como método, mas as interações interculturais como objeto de estudo na sua própria historicidade (2003; 2004). Ainda sim, cabe destacar que a ideia de transnacional pode não apagar a história nacional ou mesmo a história comparativa, e sim complexificá-las (Weinstein, 2013).

As diferentes formas como o conhecimento transita ultrapassam barreiras nacionais, de maneira que talvez, como sugere David Armitage, a história intelectual e por extensão a história da historiografia ofereçam ferramentas para uma história transnacional epistêmica (Armitage, 2013). Diante disso, as iniciativas de história da historiografia/ história intelectual global partem da globalização como dado como demonstram Iggers, Wang e Mukherjee em A global history of historiography (2008: 1), e de um cenário de predomínio de estudos de tradições nacionais ou, no máximo, da tradição ocidental, de historiografia.

No que diz respeito à produção disciplinar de conhecimento haveria uma lacuna a ser preenchida, referente à interação entre tradições ocidentais e não-ocidentais de historiografia em um contexto global. Assim, como na discussão sobre o Orientalismo trazida à baila por Edward Said, é necessário também pensarmos sobre o Ocidentalismo enquanto uma cosmovisão enraizada no dito Ocidente que influencia diversas ideologias, desumanizações e valores perversos (Margalit; Buruma, 2014; Latour, 2012). 
A questão-chave de uma história da historiografia global passa a ser a consideração do processo de globalização como uma ocidentalização de facto, ainda que pensemos na variedade e multiplicidade internas à tradição ocidental de historiografia, e nas múltiplas possibilidades de interação e resistência a ela, sem contar a riqueza e complexidade de tradições não-ocidentais de pensamento histórico, como a chinesa e a indiana (Iggers; Wang; Mukherjee, 2008: 3). A questão pode ser resumida no problema de como deixar de considerar a Europa como um "referente silencioso" no estudo do conhecimento histórico, como aponta Dipesh Chakrabarty em seu Provicializing Europe

That Europe works as a silent referent in historical knowledge becomes obvious in a very ordinary way. There are at least two everyday symptoms of the subalternity of non-Western, third-world histories. Third-world historians feel a need to refer to works in European history; historians of Europe do not feel any need to reciprocate. (...) "They" [os europeus] produce their work in relative ignorance of non-Western histories, and this does not seem to affect the quality of their work. This is a gesture, however, that "we" cannot return. We cannot even afford an equality or symmetry of ignorance at this level without taking the risk of appearing "oldfashioned" or "outdated"(Chakrabarty, 2000: 28).

Para o autor, a relação entre modernidade, e capitalismo, e o conhecimento histórico (em particular o historicismo) é inescapável. A própria história do conhecimento histórico, nomeadamente o historicismo, naturalizou a ideia de que o conhecimento nasceu na Europa e depois se irradiou pelo mundo. Essa estrutura de pensamento produziu "versões locais da mesma narrativa", substituindo a Europa por outros supostos centros locais. Assim, o historicismo "posited historical time as a measure of the cultural distance (at least in institutional development) that was assumed to exist between the West and the non-West" (Chakrabarty, 2000: 7).

Esta perspectiva é corroborada por historiadores como Jack Goody e Immanuel Wallerstein. Em O roubo da história, Goody empreende uma análise historiográfica dos textos de historiadores como Fernand Braudel, mostrando justamente como a articulação entre tempo e espaço, os pressupostos do distanciamento analítico comparativo são também europeus. Os pilares de sua perspectiva crítica se dirigem à necessidade de desnaturalizar a percepção de que os valores europeus sejam universais aliada a uma valorização qualitativa dos passados não europeus; enfim reconhecendo que a localização de eventos no tempo-espaço é uma construção epistemológica social (2006: 18-19). Nesse sentido, a dimensão global da produção e circulação de conhecimento ganha contornos de uma crítica ao capitalismo. Isso fica mais claro em textos e obras em que Immanuel Wallerstein sintetiza e difunde os resultados de 
sua obra monumental sobre o Sistema mundial moderno (publicada em vários volumes desde a década de 1980), tais como 0 universalismo europeu, em que procura explicar o compasso entre a produção de um aparato epistemológico europeu pretensamente neutro e desenraizado de sua origem e a lógica da dominação capitalista (2006: 77).

Assim, a própria globalização tomada como dado natural e inevitável é, na verdade, um dado social e historicamente construído que condiciona nosso próprio olhar sobre o mundo, e a ciência, mesmo social, é produzida a partir de uma matriz disciplinar consonante (Lander, 2000: 20-26). A partir disso, os passados nacionais locais e os projetos políticos presentes são articulados. Qualquer "metodologia" embasada em conceitos derivados do repertório moderno será insuficiente, pois analisa seus objetos com uma pretensa neutralidade que é na verdade incansável diante do enraizamento europeu dos conceitos. Interessante iniciativa da Unidade Regional de Ciências Sociais e Humanas para América Latina e o Caribe, publicada no ano 2000 e dedicada justamente a problematizar o eurocentrismo e a produção de conhecimento, é o livro La colonialidad del saber: eurocentrismo y ciencias sociales. Perspectivas latinoamericanas, em que vários textos corroboram esta ideia, tais como os de Francisco López Segrera, "Abrir, impensar, y redimensionar las ciencias sociales en América Latina y el Caribe. Es possible una ciencia social no eurocéntrica en nuestra región?", ou de Aníbal Quijano, "Colonialidad del poder, eurocentrismo y América Latina".

Insere-se nesse contexto o problema da dinâmica centro-periferia, do desenvolvimento ou desenvolvimentismo, como nos demonstra Joseph Love em A construção do Terceiro Mundo à partir da comparação das semelhanças e diferenças entre as teorias do subdesenvolvimento na América Latina, Caribe e Europa Centro-Oriental. As bases epistemológicas do par centro-periferia seriam derivações da ideologia de dominação europeia, existem meios de aproveitar as tensões produzidas por essa dualidade para pensarmos criticamente? Ou estaríamos aprisionando o pensamento em um horizonte inevitavelmente etnocêntrico?

A revista polonesa Teksty, do Instituto de Pesquisas Literárias da Academia Polonesa de Ciências, lançou num dossiê temático de 2014 justamente a pergunta: "Estudos pós-coloniais ou pós-dependência"? Como esclarece Ryszard Nycz, a pergunta é pertinente especialmente considerando os condicionantes históricos poloneses: não foram exatamente coloniais, mas certamente colaboraram para delinear os significados da dependência considerando as interaç̃̃es com os impérios Austro-Húngaro, Prussiano e Russo (2014: 5). A ideia pode ser muito útil para repensar o caso brasileiro, que engendra um curto circuito entre as noções de centro e periferia depois da independência. Enquanto um império europeu semidesenraizado na América, o Estado independente rapidamente mobilizou as linguagens da dominação, adaptando e reproduzindo o colonialismo e o imperialismo em suas zonas de influência e em 
seu próprio território ainda em dominação. 0 caso do luso-tropicalismo de Gilberto Freyre é um bom exemplo da ressignificação do passado em narrativas pós-coloniais como parte da configuração de uma modernidade periférica específica. 0 crítico Roberto Vecchi nos ajuda a entender como esse discurso de pretensa natureza pós-colonial se difunde no mundo português, especialmente na África, ganhando contornos de um discurso imperialista (Vecchi, 2014); indo mais além, como tais termos acabam por consolidar um discurso conservador sobre a "democracia racial" com forte eficácia dentro do próprio Brasil (Nicodemo, 2016: 345-346).

0 problema centro-periferia seria, então, não apenas um dado mas um processo a ser compreendido ele próprio em suas condicionantes históricas. Mas investir nesta senda requer muito cuidado com a complexidade das trocas e com a permeabilidade e adaptabilidade das formas culturais de dominação. Não se pode pressupor uma relação unilateral entre centro e periferia, mas uma teia de trocas e influências mútuas que condicionam teias de poder transnacional. Esse território movediço e instável das relações de poder, conhecimento e trocas culturais em sua própria historicidade é o ponto de partida de uma história da historiografia global.

Por sua vez, a globalização apontada como dado naturalizado e como processo histórico inevitável é algo historicamente construído que condiciona nosso próprio olhar sobre o mundo. A naturalidade com que a encaramos é uma resultante de seu alastramento como matriz disciplinar, que organiza os passados nacionais à luz de projetos políticos presentes. Por isso, qualquer "metodologia" embasada em conceitos derivados do repertório moderno será insuficiente, pois analisa seus objetos com uma pretensa neutralidade que é na verdade incansável diante do enraizamento europeu dos conceitos (Wallerstein; Medina; Bandeira, 2007). Insere-se nesse contexto o problema da dinâmica centro-periferia, do desenvolvimento, do desenvolvimentismo, da modernidade como fenômeno que se origina na Europa e se espalha pelo globo. Nessa perspectiva, a história produzida com bases nos pressupostos estabelecidos historicamente na Europa estaria condenada ao eurocentrismo? (cf. Schaub, 2016).

\section{A HISTÓRIA NÃO É UM UNIVERSAL ANTROPOLÓGICO?}

$\mathrm{O}$ historiador indiano Sanjay Seth discute como a tradição ocidental de conceber a história centrada numa ideia de Razão (com R maiúsculo) postula a noção de que o Ocidente possui historiografia (racional), enquanto outras tradições possuem mitos, épicos ou lendas. Mais do que isso, essa visão ocidental sobre a escrita da história permite que a historiografia ocidental sobre outros povos escreva suas histórias em termos alheios a esses 
próprios povos, e trate suas próprias representações (os mitos, épicos e lendas) como, no máximo, uma matéria-prima pouco confiável para a descrição de seus passados. Seth aponta como a historiografia ocidental avalia as demais tradições em uma escala de verdadeiro/falso ou verossímil/inverossímil que thes é alheia. E coloca a questão fundamental: como escrever a história de povos que não possuem essa mesma noção de história (historiografia)? Por isso, como (ou mesmo por que) escrever história em termos alheios àquelas culturas?

Seth procede à crítica do historicismo (em especial a partir de Michel Foucault), e procura apresentar uma saída à Razão ocidental como critério para a história da historiografia: a noção de tradições de raciocínio. Sua preocupação é "pluralizar" a Razão. Compreender, principalmente, que escrever História (à maneira como os europeus concebem) não é um universal antropológico (expressão de Gadamer):

Não estou afirmando, ao contrário do que frequentemente imaginam os historiadores, e do que é comumente ensinado nos departamentos de história das universidades, que o "fato" da história leva (em sociedades suficientemente alfabetizadas e "desenvolvidas") à escrita da história e ao historicismo. Viver na história, e desejar escrevê-la, não é um postulado antropológico universal (e, de modo muito mais enfático, não se enraíza em uma experiência existencial de tempo); ao invés disso, é uma maneira espećifica de conceber o mundo e estar nele, ao mesmo tempo uma tradição de raciocínio, um jeito de ser, e uma prática específica da subjetividade. A emergência dessa orientação rumo ao passado e à essência do ser é específica de certos povos (sociedades, classes), e não de outros. Está conectada a alguns fenômenos - a emergência do Estado-Nação moderno, "progresso", racionalidade científica - e não a outros, contra os quais ela pode até mesmo se definir (magia, deuses) (Seth, 2013: 185).

A visão da escrita da história como antropológico universal associa-se, como afirma Seth, a um humanismo que concebe um Homem (com H maiúsculo) universal. A saída de Seth é a proposição de que a historiografia (europeia) é um "código cultural" específico, uma forma de representar e se relacionar com o passado, entre tantas outras possíveis. Portanto, ao invés de falarmos em historiografias, falaríamos em representações do passado, conceito que pode incluir mitos, épicos e lendas em uma relação sem hierarquias com a escrita da história ocidental. De fato, essa questão não passou despercebida pelos historiadores oitocentistas, que, em última instância, não negam que a lenda é uma forma de história, ou o mito. No entanto, a diferença fundamental entre o que Seth advoga e os procedimentos dos historiadores reside em que os últimos jamais desassociaram essas formas de conhecimento histórico de um conceito de hierarquia civilizacional que minorava essas culturas. Assim, esssa abordagem permite retirar da escrita da história ocidental o "privilégio epistêmico" atribuído por ela própria em relação a outras formas de representação do passado. 
Se o que existe é não a Razão, e sim tradições de raciocínio; não a História e suas representações na escrita da história, e sim muitos passados re-presentados de muitas formas, então não podemos escrever com qualquer presunção de privilégio epistêmico. Precisamos conceber a escrita da história do modo ocidental e moderno não com um veio imperialista (não estamos corrigindo as percepções errôneas dos outros acerca dos seus passados), e sim como um exercício de tradução (estamos traduzindo as suas autodescrições em termos que fazem sentido dentro das nossas tradições intelectuais). Não se trata de recuar em nossas tradições - pois elas são o ponto de partida do nosso exercício de razão, se quisermos mesmo exercitar a razão. Só não atribuímos a elas um privilégio epistêmico a priori (Seth, 2013: 187).

Uma possibilidade para se pensar sobre o referido privilégio epistêmico da história pode ser encontrada justamente em uma abordagem interdisciplinar que dissolva e/ou problematize a distinção entre História e Etnografia/Antropologia. Manuela Carneiro da Cunha e Eduardo Viveiros de Castro (1985) utilizam os cronistas europeus como fonte para recuperar a concepção de tempo dos Tupinambá, e a centralidade da vingança nessa concepção. ${ }^{4}$ Nesse sentido, outras abordagens podem extrair, a contrapelo, dos registros existentes, as representações do passado que nos permitiriam uma nova história da historiografia na América Latina comprometida, inclusive do ponto de vista ético-político, na historicização e luta contra as várias formas de etnocídio, entendido, em especial no Brasil, como "a essência mesma da relação, de 1500 até os dias de hoje entre a forma-Estado (o Estado colonial, imperial e republicano) e a forma-ethnos (os povos indígenas) no Brasil)", ou, em outros termos, a transformação do índio em pobre (Castro, s.d).

Para Eduardo Viveiros de Castro, a definição do que é índio, ainda hoje, passa pelo reconhecimento explícito do fato de que existia um mundo social pré-colombiano e de que há uma boa quantidade de comunidades e coletivos no Brasil e em vários países latino-americanos nos dias de hoje que se sentem ligados a esse mundo de diversas formas. 0 autor destaca que um dos desafios atuais, do ponto de vista, entre outros, políitico, econômico, ético e intelectual é contribuir para o processo de retransformar os pobres em índios e não o contrário: "entendo que índio não é um conceito que remete apenas, ou mesmo principalmente, ao passado - é-se índio porque se foi índio -, mas também um conceito que remete ao futuro - é possível voltar a ser índio, é possível tornar-se índio. A indianidade é um projeto de futuro, não uma memória do passado. No dia em que os brasileiros entenderem isso, nossa relação com a "Europa' vai se resolver" (Castro, 2011: 265). Essa perspectiva, na visão do autor, pode contribuir para compreendermos, dialogarmos e pensarmos em outros modos de existência coletivos a partir das experiências dos que jamais foram modernos, isto é, em multiplicidades extramodernas, em especial as que podem ser apreendidas das questões indígenas 
(cf. também Latour, 2012). Estamos aqui, portanto, diante de um dos desafios lançados por Sanjay Seth (2013: 188): o confronto com outros modos de raciocínio (e, complementaríamos, de existência) que possam "servir para fazer com que a escrita da história deixe de ser uma prática imperialista e se torne uma prática ética".

0 debate deve passar inevitavelmente pela história institucionalizada, mas também por outras epistemes para se pensar, experimentar e relacionar com o passado. Nunca é desnecessário lembrar as estratégias de poder e dominação envolvidas na valorização, na América Latina, da palavra escrita (Rama, 2015; cf, também, entre outros, Peregrino, 2010). Esta era a única fonte válida frente à precariedade e insegurança da palavra falada. Para assegurar a posse do solo, por exemplo, exigia-se um ritual levado a cabo pelo escrivão que dava fé à palavra escrita, já que a fé se relacionava intimamente com a palavra escrita. Havia, assim, uma vida letrada e outra real que se atravessavam, hibridizavam e excluíam. ${ }^{5}$ Uma maior reflexão sobre dimensões interculturais, agenciadoras do confronto entre temporalidades ou historicidades distintas, pode ser útil também para a maior compreensão das ambiguidades dos processos de modernização da América Latina, possibilitando porvires do passado que assumam o conflito e sejam mais abertos, heterogêneos, híbridos e democráticos (cf. Canclini, 2006). Nessa direção, ainda segundo Canclini, as noções de centro e periferia podem também ganhar em potência se pensadas junto com outras noções como circuitos e fronteiras, bem como com maior atenção à transposição constante das fronteiras, à transnacionalização da cultura efetuada pelas tecnologias comunicacionais e às críticas às lógicas do crescimento, progresso, aceleração e a destruição da natureza (cf, entre outros, Latouche, 2009; Domasnka, 2010).

\section{À GUISA DE CONCLUSÃO}

$\mathrm{E}$ ste texto procurou mapear, ainda que de forma lacunar, os debates acerca da relação entre eurocentrismo e escrita da história, assinalando seus possíveis aproveitamentos, desdobramentos e consequências para a história da historiografia. Uma pergunta aparentemente simples - tal como é possível pensar a história fora de parâmetros europeus? - se desdobra num panorama de discussões altamente delicado e complexo. Conceitualmente, o imperativo de lidar com o caráter restritivo e historicamente condicionado do que podemos entender por história/historiografia, e com as alternativas daí resultantes, nos leva a dois caminhos: o de assumirmos como história/historiografia apenas o que é assim definido a partir da tradição europeia, e nos limitamos a uma história da historiografia dessa prática e conceito, ou encararmos o desafio de pensar outras apresentações, representações, narrativas e experiências do passado e reformularmos nossas histórias da historiografia para torná-las, 
de fato, globais ou transnacionais, sob o risco de negarmos a própria pertinência da historiografia como disciplina.

É necessário nesse sentido reconhecermos os limites deste texto, que procurou analisar o debate sobre o eurocentrismo na historiografia, mas sem deixar abandonar um compromisso, ou até esperança, com a pertinência da história da historiografia e seus parâmetros disciplinares. Os esforços de Eduardo Viveiros de Castro que procuramos rapidamente ilustrar vão no sentido de pensar a história para além de epistemes familiares.

Essas discussões apontam para as possibilidades de renovação ou de aprimoramento do repertório de temas e ferramentas de pesquisa dos historiadores brasileiros, problema que se entrelaça por sua vez com o contexto de crise em todas as ciências humanas. Para Ewa Domanska, a teoria nas ciências sociais parece "um passo atrás do que ocorre no mundo contemporâneo em termos de cataclismas ambientais, crise nas mudanças climáticas, em termos de tecnologia, engenharia genética e nanotecnologia (somado à difusão do capitalismo global)". A autora vai mais longe do que a crítica ao eurocentrismo advogando uma abordagem "não-antropocêntrica" (Domanska, 2010: 119). A história da historiografia pode agir com mais liberdade e agilidade abraçando alguns desses temas em perspectivas transnacionais e globais, começando por fazer perguntas atuais para a nossa tradição de escrita da história, procurando pensar temas como a consciência ecológica, a democracia, o capitalismo, a tecnologia, o preconceito, o racismo, o machismo, entre tantos outros. Entendemos que discutir o eurocentrismo na escrita da história é certamente um bom ponto de partida.

\section{NOTAS}

1 A base de Colmenares para pensar o paralelo entre romance e história na Europa oitocentista é Roland Barthes, e sua análise de Michelet. Ainda que de forma lateral, cabe mencionar importante aspecto que vem sendo destacado por alguns autores, a saber: a perda de prestígio e/ou centralidade da historiografia (e língua) francesa no mundo. A esse respeito, no interior dos debates sobre a "história-mundo", Patrick Boucheron, por exemplo, afirma em 2013: "atolados nas querelas suscitadas pelo embaraçoso legado braudeliano, extraviados pelas sereias da microstoria que fazia a história em migalhas, incapazes de se dar conta do quanto a França encolhera, transformada em potência mediana da historiografia, exportando sua French Theory como outros exportam conhaque ou bolsas (ou seja, como um produto de luxo para elites mundializadas), deixavam, totalmente, de responder ao chamado da World History" (Boucheron, 2015: 7).

2 Schwarz (1973); debatido em Franco (1976) e Paltí (2007).

3 A história da historiografia pode apreender muito com os "subaltern studies" nesse sentido. A do caso brasileiro desta trajetória permitirá portanto compreender que, em um contexto de revisão dos parâmetros europeus de pensamento, a "periferia" foi um lugar de experiências de vanguarda na reelaboração de ferramentas que permitiram a reconfiguração das formas de representação do passado (cf. Chakrabarty, 2000). A 
ressignificação do passado em novas narrativas pós-coloniais, como parte da configuração de uma modernidade periférica específica, foi estudada por Roberto Vecchi, que examinou o "Luso-tropicalismo", a construção do discurso de Gilberto Freyre sobre o colonialismo português apropriada (com apoio do autor) pelo regime pós-colonial salazarista português, observando a necessidade de a teoria pós-colonial atentar para a análise dos discursos (Vecchi, 2014).

4 É digno de nota que só recentemente e de forma bastante lenta a importante obra de Eduardo Viveiros de Castro começou a ser lida e discutida pelo campo da teoria e história da historiografia. Ainda que incipiente, esse interesse mostra algum tipo de deslocamento em curso. Cf., também legelski e Pagden (1982). As reflexões de Lévi-Strauss e Marshall Sahlins no que concerne ao questionamento das fronteiras entre história e antroprologia também deveriam merecer maior visitação da nossa parte.

5 A questão da oralidade mobiliza diversos domínios. Cf, por exemplo, Ong (1998) e Vansina (s.d). Além disso, é preciso frisar que em uma perspectiva atlântica, desde a "primeira modernidade", há "complexos emaranhados que entrelaçam vários grupos étnicos. 0 Atlântico foi uma co-criação de muitos povos que se misturaram e lutaram uns com os outros. (...) Todo grupo ameríndio que teve contato direto ou indireto com gente vinda de fora das Américas acabou por se reconfigurar por conta dessa integração agressiva de estranhos, que incluía os africanos (Snyder, 2010). As primeiras cidades europeias na bacia atlântica não eram compostas de colonos europeus, mas de africanos. (...) No entanto, apesar de toda essa nova consciência das dimensões atlântica e global da história da primeira modernidade, o campo ainda segue atrelado a histórias nacionais" (Cañizares-Esguerra; Fernandes \& Martins, no prelo). Cf. também Cañizares-Esguerra \& Seeman (2006).

\section{REFERÊNCIAS BIBLIOGRÂFICAS}

ARAUJO, Valdei Lopes de. A experiência do tempo: conceitos e narrativas na formação nacional brasileira (1813-1845). São Paulo: Hucitec, 2008.

Historiografia, nação e os regimes de autonomia na vida letrada no Império do Brasil. Varia História (UFMG. Impresso), v. 31, p. 364-400, 2015 a.

The history of concepts and the history of historiography: a Brazilian trajectory. In: MATA, Sérgio Ricardo da; PEREIRA, Luisa Rauter; MARTINS, Luiz Estevam (org.). Contributions to theory and comparative History of Historiography traditions. German and Brazilian perspectives. 1ed. Frankfurt am Main: Peter Lang, 2015b, p. 175-193.

\& PIMENTA, João Paulo G. História (conceito de). In: FERES JÚNIOR, João (org.). Léxico da história dos conceitos políticos do Brasil. Belo Horizonte: Editora da UFMG, 2009, p. 119-140.

ARMITAGE, David. The international turn in itellectual history. In: MCMAHON, Darrin M. \& MOYN, Samuel (eds). Rethinking modern European intellectual history. New York: Oxford University Press , 2014, p. 232-252.

BOUCHERON, Patrick \& DALALANDE, Patrick. Por uma história-mundo. Belo Horizonte: Autêntica, 2015.

CANCLINE, Nestor García. Culturas hibridas. estratégias para entrar e sair da modernidade. São Paulo: USP, 2006.

CAÑIZARES-ESGUERRA, Jorge \& SEEMAN, Erik R. (eds). The Atlantic in global history, 1500-2000. NJ: Prentice Hall, 2006. 
CAÑIZARES-ESGUERRA, Jorge; FERNANDES, Luiz Estevam de 0. \& MARTINS, Maria Cristina Bohn. As Américas na primeira modernidade. Curitiba: Prismas, 2017 (no prelo).

CASTRO, Eduardo Viveiros de. Sobre os modos de existência dos coletivos extramodernos (s/data). In: https:// www.academia.edu/21559561/Sobre_0_modo_de_existencia_dos_coletivos_extramodernos

Sobre a noção de etnocídio, com atenção especial para o caso brasileiro. In: https://www. academia.edu/25782893/Sobre_a_no\%C3\%A7\%C3\%A30_de_etnoc\%C3\%ADdio_com_especial_ aten\%C3\%A7\%C3\%A30_ao_caso_brasileiro

\& CUNHA, Manuela Carneiro da. Vingança e temporalidade: os Tupinambá. Journal de la Société des Américanistes, tome 71, 1985, p. 191-208.

CHAKRABARTY, Dipesh. Provincializing Europe: postcolonial thought and historical difference. Princeton: Princeton University Press.

The calling of history: Sir Jadunath Sarkar ad his empire of truth. Chicago: University of Chicago, 2015.

CHRISTINO, Beatriz Protti. A rede de Capistrano de Abreu: uma análise historiográfica do rã-txa hu-ni-ku- i em face da sul-americanística dos anos 1890-1929. Tese de doutorado. Programa de Pós-graduação em Semiótica e Linguística Geral, Universidade de São Paulo, 2006.

COLMENARES, German. Convenciones contra la cultura. Ensayos sobre la historiografia hispanoamericana del siglo XIX. Bogotá: TM Editores, 1986.

DAVIS, N. Z. Decentering history: local stories and cultural crossings in a global world. History and Theory, v. 50, n. 2, p. 188-202, 2011.

DETIENNE, Marcel. Comparar o incomparável. São Paulo: Ideias \& Letras, 2004.

DOMANSKA, Ewa. Beyond anthropocentrism in historical studies. Historein, v. 10, 2010.

FRANCO, Maria Sylvia Carvalho. As idéias estão no lugar. Cadernos de Debate 1. História do Brasil. São Paulo: Brasiliense, 1976.

GOODY, Jack. O roubo da história: como os ocidentais se apropriaram das ideias e invenções do Oriente. São Paulo: Ed. Contexto, 2008.

IEGELSKI, Francine. História e antropologia: notas de trabalho sobre as correlações entre modernidade, presentismo e perspectivismo ameríndio. Disponível em https://www.academia.edu/29618008/Hist\%C3\%B3ria_e_Antropologia_notas_de_trabalho_sobre_as_correla\%C3\%A7\%C3\%B5es_entre_modernidade_presentismo_e_ perspectivismo_amer\%C3\%ADndio, acesso em 5 de dezembro de 2016.

IGGERS, Georg G.; WANG, Q. E. \& MUKHERJEE, Supriya. A global history of modern historiography. Harlow, England: Pearson Longman, 2008.

LANDER, Edgardo (ed.). La colonialidad del saber: eurocentrismo y ciencias sociales. Perspectivas latinoamericanas. Buenos Aires: Consejo Latinoamericano de Ciencias Sociales - CLACSO, 2000.

LATOUCHE, Serge. Pequeno tratado do crescimento sereno. São Paulo: Martins Fontes, 2009.

LATOUR, Bruno. Enquête sur les modes d'existence. Une anthropologie des modernes. Paris: La Découverte, 2012. 
LÓPEZ SEGRERA, Francisco. Abrir, impensar, y redimensionar las ciencias sociales en América Latina y el Caribe. In: LANDER, Edgardo (ed.). La colonialidad del saber: eurocentrismo y ciencias sociales. Perspectivas latinoamericanas. Buenos Aires: Consejo Latinoamericano de Ciencias Sociales - CLACSO, 2000.

LORENZ, C.; BERGER, S. \& MELMAN Melman, B. (eds.). Popularizing national pasts: 1800 to the present. New York: Routledge, 2012.

LOVE, Joseph L. A construção do Terceiro Mundo. Teorias do subdesenvolvimento na Romênia e no Brasil. Trad. Patrícia Zimbres. Rio de Janeiro: Paz e Terra, 1998.

MARGALIT, Avishai \& BURAMA, lan. Occidentalism: the West in the eyes of its enemies. New York: The Penguin Press, 2004.

MARQUESE, Rafael \& PIMENTA, João Paulo. Tradições de história global na América Latina e no Caribe. História da Historiografia, n. 17, 2015.

MAUREL, C. La world/global history: questions et débats. Vingtième Siècle. Revue d'Histoire, n. 104, p. 153-166, 2009.

MAZLISH, Bruce. Comparing global history to world history. Journal of Interdisciplinary History, vol. 28, n. 3, 1998, p. 385-395.

MEJÍA, Sergio. La noción de historicismo americano y el estudio de las culturas escritas americanas. Historia Crítica Edición Especial, Bogotá, nov. 2009, p. 246-260.

NICODEMO, Thiago Lima. 0 modernismo de estado e a política cultural brasileira na década de 1940: Candido Portinari e Gilberto Freyre nos EUA. Revista Landa, vol. 5, n.1, 2016.

NYCZ, Ryszard. Polish post-colonial and/or post-dependence studies. Teksty Drugie, n. 1, 2014.

ONG, Walter. Oralidade e cultura escrita: a tecnologização da palavra. Campinas: Papirus, 1998.

PAGDEN, Anthony. The fall of natural man: the American Indian and the origins of comparative anthropology. Cambridge: Cambridge University Press, 1982.

PALTÍ, Elias. El tiempo de la política. Buenos Aires: Siglo XXI, 2007.

PURDY, Sean. A história comparada e o desafio da transnacionalidade. Revista de História Comparada, Rio de Janeiro, 6-1: 64-84, 2012.

QUIJANO, Aníbal. Colonialidad del poder, eurocentrismo y América Latina. In: LANDER, Edgardo (ed.). La coIonialidad del saber: eurocentrismo y ciencias sociales. Perspectivas latinoamericanas. Buenos Aires: Consejo Latinoamericano de Ciencias Sociales - CLACSO, 2000.

RAMA, Ángel. A cidade das letras. São Paulo: Boitempo Editorial, 2015.

SAID, E. Orientalismo: o Oriente como invenção do Ocidente. São Paulo: Cia das Letras, 2000.

SALVADOR, Frei Vicente do. História do Brasil. São Paulo e Rio: Weiszflog Irmãos, 1918.

SÁNCHEZ CUERVO, Antolín \& ZERMEÑO PADILLA, Guillermo. El exilio español del 39 en México. Mediaciones entre mundos, disciplinas y saberes. México: El Colegio de México, 2014. 
SCHAUB, Jean-Frédéric. L'histoire européenneest-elle condamnéeàl'eurocentrisme. Disponível em:https://www. academia.edu/31031068/LHISTOIRE_EUROP\%C3\%89ENNE_EST-ELLE_CONDAMN\%C3\%89E_\%C3\%80_ LEUROCENTRISME.

SCHWARZ, Roberto. As ideias fora do lugar. Estudos CEBRAP, n. 3, 1973.

SETH, Sanjay. Razão ou raciocínio? Clio ou Shiva? História da Historiografia, Ouro Preto, n. 11, abril 2013, p. 173-189.

SOARES, G. P. Letramento e mediações culturais em pueblos indígenas do centro sul do México no século XIX. História Revista(UFG), v. 15, p. 97-118, 2010.

SOUZA, Gabriel Soares de. Tratado descriptivo do Brazil em 1587. Rio de Janeiro: Typographia Universal de Laemmert, 1851.

TAYLOR, Diana. O arquivo e o repertório: performance e memória cultural nas Américas. Belo Horizonte: UFMG, 2013.

TURIN, R. 0 'selvagem' entre dois tempos: a escrita etnográfica de Couto de Magalhães. Varia História(UFMG. Impresso), v. 28, p. 781-803, 2012.

VANSINA, Jean. A tradição oral e sua metodologia. In: História geral da África - Metodologia e pré-história de África. São Paulo: Ática / UNESCO, s/data.

VECCHI, Roberto. A periferia como obra: modernidades excêntricas a rearranjos luso-tropicalistas. Revista do Instituto de Estudos Brasileiros, n. 58, p. 17-34, jun. 2014

VENGOA, Hugo Fazio. El mundo global: una historia. Bogotá: Ediciones Uniandes, 2013.

WALLERSTEIN, I. M., MEDINA, B. \& BANDEIRA, L. A. M. O universalismo europeu: a retórica do poder. São Paulo: Boitempo, 2007

WEINSTEIN, Barbara. Pensando a história fora da nação: a historiografia da América Latina e o viés transnacional. Revista Eletrônica da ANPHLAC, n. 14, p. 13-29, jan./jun. 2013.

WERNER, M. \& ZIMMERMANN, B. Penser I'histoire croisée: entre empirie et réflexivité. Annales. Paris, 2003.

——_. De la comparaison à I'histoire croisée. Paris: Seuil, 2004.

ZERMEÑO PADILLA, Guillermo. Historia, experiencia y modernidad en Iberoamerica, 1750-1850. Almanack Braziliense. São Paulo: Instituto de Estudos Brasileiros da Universidade de São Paulo, n.7, maio de 2008. 